Int. J. Electrochem. Sci., 14 (2019) 9552 - 9561

International Journal of

ELECTROCHEMICAL

SCIENCE

WWW.electrochemsci.org

\title{
An Electrochemical Sensitive Sensor for Determining Sulfamethoxazole Using a Modified Electrode Based on Biosynthesized NiO Nanoparticles Paste Electrode
}

\author{
Sadegh Salmanpour ${ }^{1}$, Mohammad A. Khalilzadeh ${ }^{1, *}$, Hassan Karimi-Maleh $^{2,3}$ and Daryoush Zareyeea \\ ${ }^{1}$ Department of Chemistry, Qaemshahr Branch, Islamic Azad University, Qaemshahr, Iran \\ ${ }^{2}$ Department of Chemical Engineering, Laboratory of Nanotechnology, Quchan University of \\ Technology, Quchan, Iran \\ ${ }^{3}$ Department of Applied Chemistry, University of Johannesburg, P. O. Box 17011, Doornfontein \\ Campus, 2028, Johannesburg, South Africa, \\ *E-mail: khalilzadeh73@gmail.com
}

doi: $10.20964 / 2019.10 .03$

Received: 6 June 2019 / Accepted: 28 July 2019 / Published: 30 August 2019

In this research, we describe a new type of sulfamethoxazole electrochemical sensor based on a carbon paste electrode (CPE) modified with $\mathrm{NiO}$ nanoparticle (NiO-NPs) and 1-methyl-3-octylimidazolium tetrafluoroborate (1M3OIMZTFB). The $\mathrm{NiO}$ nanoparticle was biosynthesized with a diameter of $\sim 18.0$ $\mathrm{nm}$ by Mentha aquatic extract and characterized by AFM, FESEM, XRD and EDS methods. The oxidation peak of sulfamethoxazole was recorded at $+1130 \mathrm{mV}$ and $+995 \mathrm{mV}$ at surface of CPE and 1M3OIMZTFB/NiO-NPs/CPE. Meanwhile, the oxidation signal of sulfamethoxazole was improved by 20.32 times compared to unmodified CPE. The 1M3OIMZTFB/NiO-NPs/CPE exhibited good catalytic activity toward sulfamethoxazole with a dynamic range $0.003-400.0 \mu \mathrm{M}$ and limit of detection $1.0 \mathrm{nM}$. The 1M3OIMZTFB/NiO-NPs/CPE was used as useful tool for determination of sulfamethoxazole in real samples.

Keywords: Sulfamethoxazole, NiO nanoparticle, Biosynthesis, Electrochemical Sensor

\section{$\underline{\text { FULL TEXT }}$}

(C) 2019 The Authors. Published by ESG (www.electrochemsci.org). This article is an open access article distributed under the terms and conditions of the Creative Commons Attribution license (http://creativecommons.org/licenses/by/4.0/). 